\title{
$\operatorname{movimento~}_{\text {revis }}$
}

faculdade de educação - programa de pós-graduação em educação

universidade federal fluminense

issn 2359-3296

ano 3 número 4 - 2016

\section{A INFLUÊNCIA DAS POLÍTICAS NO CURRÍCULO OFICIAL NA VISÃO DAS COORDENADORAS PEDAGÓGICAS}

\author{
Jane Cordeiro de Oliveira ${ }^{1}$
}

\section{Resumo}

O artigo mostra a influência das políticas educacionais globais no currículo da Cidade do Rio de Janeiro e como interferem na prática docente, na visão de coordenadoras pedagógicas entrevistadas. Apresentamos o panorama das políticas e seus documentos oficiais: Orientações Curriculares, Descritores e Cadernos de Apoio Pedagógico. Os dados revelaram que as coordenadoras consideram o currículo como "importante" pois os conhecimentos neles contidos são avaliados. Os documentos curriculares tolhem a autonomia do professor pois só conhecimentos mensurados são considerados relevantes.

Palavras- chave: políticas educacionais, documentos curriculares, avaliação.

\section{ABSTRACT}

The article shows the influence of global policies in the curriculum of Rio de Janeiro city and how they interfere with the teaching practice in the view of educational coordinators interviewed. We present the overview of the policies and their official documents: Curriculum Guidelines, Descriptors and Books of Pedagogical Support. The data revealed that the coordinators consider the curriculum "important" because the knowledge contained in them are evaluated. The curriculum documents stunt the teacher autonomy because only the measured knowledge is considered relevant.

Keywords: educational policies, curriculum documents, evaluation.

1 Doutora em Educação Brasileira formada pela Pontfícia Universidade Católica do Rio de Janeiro. Professora da Escola Municipal Juliano Moreira, RJ. janecoliveira@yahoo.com.br 


\section{INTRODUÇÃO}

Este artigo é parte de uma pesquisa qualitativa realizada em 2013 e 2014, cujo objetivo foi mostrar como as políticas educacionais no campo macro (global e nacional) influenciam as políticas locais, neste contexto, a Cidade do Rio de Janeiro, e consequentemente, nos comportamentos dos profissionais que trabalham no campo micro (escola). Com isso, apresentamos as seguintes questões: a) Como as políticas educacionais globais influenciam as políticas do campo micro? b) Quais são os documentos curriculares que representam as políticas educacionais da Cidade do Rio de Janeiro? c) Qual é a opinião das coordenadoras pedagógicas que trabalham nas escolas públicas da Cidade do Rio de Janeiro a respeito da influência dos documentos curriculares da Secretaria Municipal de Educação (SME/Rio) nas práticas pedagógicas docentes?

Os sujeitos selecionados em nossa amostra foram dezoito (18) coordenadoras pedagógicas atuantes em escolas públicas municipais da Cidade do Rio de Janeiro que obtiveram bom desempenho na Prova Brasil 2011.

Nossos referenciais teórico-analíticos foram Ball (2001a; 2001b; 2002; 2004; 2012) e Carnoy (2002) revelando como os documentos curriculares da Secretaria Municipal de Educação (SME/Rio) influenciam o trabalho exercido por professores e gestores no espaço escolar junto aos alunos. Marcondes, Leite e Oliveira (2012), Marcondes (2013) e Marcondes e Moraes (2013) nos auxiliaram na compreensão do papel do coordenador pedagógico no processo de mediação entre as políticas e os professores.

Nos remetemos ao conceito de Estado regulador trazido por Ball (2004) que molda os textos das políticas sob o viés empresarial e regula os comportamentos dos profissionais que trabalham na escola, interferindo nos 
processos pedagógicos em sala de aula através do monitoramento feito com avaliações externas periódicas nas escolas.

No contexto micro apresentamos um breve histórico a respeito dos mecanismos de influência das macropolíticas na constituição dos textos dos discursos curriculares das políticas da SME/Rio mostrando como os discursos curriculares vindos da SME/Rio sofrem a influência das macropolíticas nos campos global e nacional. Os documentos curriculares da SME/Rio são as Orientações Curriculares, Descritores, Cadernos de Apoio Pedagógico. E os instrumentos de avaliação são as Provas Bimestrais de Língua Portuguesa, Matemática e Ciências enviadas bimestralmente a todos os alunos das escolas da rede pública municipal.

A pesquisa teve como instrumento de coleta de dados entrevistas semiestruturadas realizadas nos locais de trabalho das coordenadoras pedagógicas e os assuntos principais dissertaram a respeito dos materiais curriculares enviados pela SME/Rio às escolas. Para análise dos dados coletados utilizamos a análise de conteúdo dos documentos curriculares e das trasncrições das entrevistas.

Durante o processo de análise das entrevistas percebemos que coordenadoras pedagógicas consideram os documentos curriculares enviados pela SME/Rio como "importantes" porque os conteúdos contidos nos documentos são avaliados periodicamente por avaliações em larga escala. Elas também relataram que sentem "pressão" por parte da SME/Rio para obter um bom desempenho nas provas.

Nas considerações finais observamos que as políticas educacionais influenciam a constituição dos documentos curriculares no trabalho pedagógico desenvolvido pelos professores em sala de aula. As políticas locais indicam que há indícios de controle de desempenho das escolas e padronização curricular por parte da SME/Rio sobre as escolas e o trabalho dos professores. 


\section{OS CONTEXTOS GLOBAL E NACIONAL}

O contexto global revela um fortalecimento do modelo político neoliberal a partir das décadas de 1980 e 1990, representado pelos governos Tatcher no Reino Unido, Khol na Alemanha e Reagan nos Estados Unidos ${ }^{2}$. As diretrizes neoliberais utilizadas nestes países são resumidas em: a) aumento das taxas de juros; b) corte dos gastos em políticas sociais; c) implantação de programas de privatização de empresas estatais; d) aumento de gastos militares, principalmente nos Estados Unidos.

Esta concepção de economia vem se afirmando com as mudanças do papel do "Estado de bem-estar", predominante na Europa após a Segunda Grande Guerra, que se caracterizou como corporativista, nacionalista e provedor, para "Estado regulador" agindo como "negociante", promovendo a competição econômica do livre-mercado, assim como a descentralização/centralização de suas ações. O Estado passa a ser descentralizado quando exerce a função de "provedor" e centralizado quando exerce a função de "auditor", avaliando resultados e criando metas, de acordo o modelo de performatividade associado a nos ideais empresariais (BALL, 2004).

As políticas educacionais neoliberais se difundiram com a globalização da economia e a inovação tecnológica transformando o setor público, as relações sociais, e de governança, modificando as responsabilidades do Estado com a introdução das leis do livre mercado nas diretrizes das políticas públicas. Ball cita como exemplo algumas experiências educacionais dos Estados Unidos para exemplificar a influência do gerencialismo empresarial nas políticas

\footnotetext{
2 Margaret Tatcher foi primeira ministra do Reino Unido de 1979 a 1990 . Helmut Kohl foi primeiro ministro da Alemanha Ocidental entre 1982 e 1990 e primeiro ministro da Alemanha após sua unificação, de 1990 a 1998. Ronald Reagan foi presidente dos Estados Unidos em dois mandatos consecutivos de 1981 a 1989.
} 
públicas educacionais. Ele afirma que: "a educação está cada vez mais sujeita a pressupostos e prescrições normativas do "economicismo" (2004, p.1111).

Esta ideologia estendeu sua influência nos países da América Latina através de organismos financeiros internacionais como o Banco Mundial (BM), Fundo Monetário Internacional (FMI) e a Organização Mundial de Comércio (OMC), sob a bandeira de combate ao endividamento externo e interno dos países em desenvolvimento. Os organismos financeiros elaboram e impõem medidas de forte impacto na estrutura socioeconômica destes países incluve, o Brasil. As estratégias utilizadas para tal foram: a) privatização das empresas estatais; b) flexibilização de leis trabalhistas; c) enfraquecimento das instituições sindicais; d) fortalecimento da moeda nacional; e) congelamento de salários de trabalhadores dos setores público e privado; f) aumento das taxas de juros para financiamento bancário; g) descentralização de políticas sociais, como por exemplo, a Educação (CARNOY, 2002).

A política brasileira, no início da década de 1980, passou por um processo de redemocratização, promovida pelo presidente Figueiredo³. O setor econômico já revelava sinais da influência do neoliberalismo global, pois, as ditaduras militares existentes dos países sul-americanos, neste período, entram em fase de esgotamento.

No campo das políticas educacionais, no governo do presidente Fernando Henrique Cardoso $^{4}$ foram adotadas medidas que viessem a contemplar os indicadores das políticas do Banco Mundial (BM) para o Brasil, como a publicação dos Parâmetros Curriculares Nacionais (PCNs) (BRASIL, 1998) que têm como intuito prover indicadores dos conteúdos a serem testados nos sistemas de avaliação nacional. A TV Escola (BRASIL, 2012a) foi criada com o

\footnotetext{
${ }^{3}$ O presidente João Baptista de Oliveira Figueiredo, último presidente do regime militar que governou o Brasil de 15 de março de 1979 a 15 de março de 1985.

${ }^{4}$ Fernando Henrique Cardoso foi ministro da fazenda no governo do presidente Itamar Franco durante a implantação do Plano Real e governou o Brasil por dois mandatos consecutivos de 1995 a 2003.
} 
objetivo de servir como instrumento de formação continuada docente à distância abrangendo todo o território nacional, através de sinal de satélite.

De acordo com a Lei de Diretrizes e Bases da Educação (LDB) (BRASIL, 1996a), projetos como Fundo Nacional de Desenvolvimento da Educação (FNDE) (BRASIL, 1968) e o Fundo Nacional de Desenvolvimento do Ensino Fundamental (FUNDEF) (BRASIL, 1996b), foram implantados com a finalidade de distribuir os investimentos governamentais diretamente às escolas de ensino fundamental, principalmente, através de compra e distribuição de livros didáticos e ajuda financeira direta às unidades escolares, o chamado Programa Dinheiro Direto na Escola (PDDE) (BRASIL, 2015). Com isso, foram criados pelo Estado brasileiro mecanismos de descentralização, fiscalização e acompanhamento à distância sob a forma de repassar às comunidades dos municípios, as responsabilidades de acompanhamento e fiscalização escolar, sob a bandeira da "gestão democrática das escolas" (CARNOY, 2002).

O governo Lula ${ }^{5}$ cria o Fundo de Manutenção e Desenvolvimento da Educação Básica e de Valorização dos Profissionais da Educação (FUNDEB) (BRASIL, 2007), que amplia o atendimento financeiro do Ensino Fundamental para a Educação Infantil e Ensino Médio, acentuando o controle do Ministério da Educação (MEC) sobre as escolas públicas brasileiras através do fortalecimento dos sistemas de avaliações nacionais, incluindo publicação do posicionamento das instituições escolares em relação às metas estabelecidas pelo MEC para o crescimento dos níveis de desempenho escolar nas esferas nacional, regional, estadual e municipal, como, por exemplo, o Índice de Desenvolvimento da Educação Básica (IDEB) (BRASIL, 2012b). Este referencial foi criado com o objetivo de fiscalizar o desempenho escolar $\mathrm{e}$ direcionar os investimentos para as instituições escolares que cumprem as metas de desempenho estabelecidas pelo MEC.

5 Luís Inácio Lula da Silva foi eleito presidente do Brasil e governou dois mandatos consecutivos no período de 2003 a 2011. 
Ball (2004) afirma que as diretrizes onde o Estado passa a ser regulador, revelam como as políticas internacionais influenciam diretamente nas políticas nacionais dos países em desenvolvimento. As ferramentas do Estado regulador utilizadas para o controle descentralizado são: a performatividade e a responsabilização. Estas ferramentas viabilizam o controle do Estado sobre as instituições educativas inserindo culturas, práticas, e subjetividades oriundas do setor privado, sem parecer fazê-las. Ball afirma que "a performatividade é uma tecnologia, uma cultura e um modo de regulação (...) como meios de controle" (2002, p.4). A responsabilização segundo Freitas (2013) é considerada como uma "auditoria" efetuada pelo Estado às escolas, nos moldes dos modelos empresariais.

A respeito das macropolíticas, Carnoy (2002) aponta para o desequilíbrio entre as economias dos países desenvolvidos e as fragilizadas economias dos países mais "pobres". Ele afirma que a globalização promoveu um enfraquecimento das economias nacionais $e$, consequentemente, uma interferência sistemática das políticas internacionais que priorizam a competitividade, expondo as economias dos países mais fragilizados a uma competição desigual com os países desenvolvidos. Essa interferência é sentida em todos os setores, não só no econômico, mas, no social, nas relações de trabalho e no campo educacional. O autor chama a atenção para a constituição de uma série de reformas sofridas pelas políticas educacionais, que foram promovidas pelo Banco Mundial (BM), interferindo na legislação dos países da América do Sul e do Brasil e, consequentemente, na educação pública municipal da Cidade do Rio de Janeiro. A primeira delas é a descentralização que confere aos municípios a gestão das redes públicas escolares de Ensino Fundamental, o que Carnoy (2002) denomina de "municipalidade".

As políticas de responsabilização, são definidas por Ball (2004) como ferramentas de padronização sobre as instituições escolares através de indicações unificação do currículo e estabelecimento de metas para o desempenho das escolas, influenciando o comportamento de gestores e 
professores fazendo com que valores como cooperação sejam substituídos pela competição e a pedagogia das aprendizagens, substituída pela pedagogia do desempenho classificatório.

Ball (2002) afirma que as políticas de performatividade oneram os profissionais que trabalham na escola responsabilizando-os pelo fracasso ou sucesso do desempenho discente sem levar em conta as peculiaridades de cada unidade escolar, com isso, há uma interferência direta no comportamento dos docentes e gestores em relação aos alunos. Para ele, o desempenho é uma forma de associar a produtividade à "qualidade" 6 utilizando como estratégias as premiações de escolas, vinculadas ao desempenho discente nas avaliações de larga escala.

Os indicativos de "qualidade" na educação pública, de acordo com a LDB (BRASIL, 1996) estão diretamente vinculados à "pluralidade de ideias", porém, nas políticas em vigor na SME/Rio, o termo "qualidade" passa a ser associado ao desempenho discente nas provas veiculadas pela SME/Rio e Prova Brasil (BRASIL, 2011), conforme podemos observar no trecho a seguir:

O PREFEITO DA CIDADE DO RIO DE JANEIRO, no uso das atribuições que the são conferidas pela legislação em vigor $\mathrm{e}$ considerando a necessidade de estabelecer critérios, padrões e normas de avaliação de desempenho das Unidades Escolares pertencentes à Secretaria Municipal de Educação do Rio de Janeiro; e considerando, ainda, o propósito de reconhecer as equipes escolares, que se destaquem no ensino-aprendizagem, DECRETA:

Art. $1^{\circ}$ Fica instituído o Prêmio Anual de Desempenho, a ser concedido aos servidores lotados nas Unidades Escolares da Rede Pública do Sistema Municipal de Ensino (...).

Art. $2^{\circ}$ O Prêmio será concedido aos servidores das Unidades Escolares que atingirem, a cada dois anos, as metas de acréscimo previstas com relação ao IDEB - Índice de Desenvolvimento da Educação Básica -, nos anos ímpares, e no IDERIO - Índice de Desenvolvimento da Educação do Município do Rio de Janeiro, nos anos pares.

Art. 3응 0 Prêmio, a que se reporta este Decreto, tem por objetivo recompensar os servidores que conjuguem esforços, com vistas à

${ }^{6}$ Conceito de "qualidade" tratado neste texto está vinculado ao desempenho, nos moldes da performatividade (BALL, 2001a). 
melhoria na qualidade do ensino-aprendizagem de seus alunos (RIO DE JANEIRO, 2011).

Carnoy apresenta a chamada "implantação de padrões educativos" cujas características são a centralização e a reestruturação da escola ampliando controle sobre o trabalho docente (2002, p.57), que, no Brasil, chamamos de "metas da educação", caracterizados como índices pré-estabelecidos a serem alcançados pelas escolas através do desempenho positivo em avaliações sistêmicas de âmbito nacional, cruzados com os índices de aprovação de cada escola, conforme o Índice de Desenvolvimento da Educação Básica (IDEB) (BRASIL, 2012b). Estas políticas são implantadas sem a participação de escolas, comunidade escolar e professores.

O termo "qualidade", de acordo com Carnoy (2002), está ligado à "eficácia e eficiência", conceitos relacionados às teorias econômicas e de administração empresarial. Neste caso, de acordo com as novas concepções de políticas educacionais, a escola passa a fazer parte de uma grande engrenagem que visa o cumprimento de metas com o mínimo de investimentos. Ball (2001a) é mais contundente em suas críticas, pois, ele considera que o estudante, nestas políticas, é mercantilizado, avaliado e posicionado de acordo com as regras de mercado educacional.

Carnoy revela que a "gestão racionalizada dos recursos destinados à educação" (2002, p.61) buscam maior aproveitamento a custos baixos, sob a bandeira da "melhoria da qualidade da educação" (Ibid. 2002, p.25). Estas deliberações foram trazidas pelo Banco Mundial (BM) que apoia financeiramente e gerencialmente os esforços dos governos na melhoria dos equipamentos pedagógicos, formação continuada docente e instauração de premiações para professores e escolas que conseguem atingir as metas estabelecidas, criando um sistema de competitividade entre professores e gestores das escolas possibilitando a desconstrução da consciência de classe entre os profissionais docentes. 
Outra questão relevante nestas políticas é a redução do poder criativo do professor ao delimitá-lo às prescrições existentes no currículo oficial que periodicamente passa por avaliações externas. Este tipo de gestão uniformiza escolas de diferentes realidades, desconsiderando suas peculiaridades como, por exemplo, escolas localizadas em áreas consideradas "de risco" por serem extremamente violentas, em locais de extrema pobreza ou escolas rurais que dispõem de poucos recursos.

Para Marcondes e Moraes (2013) o currículo padronizado e focado no desempenho escolar tolhe a autonomia pedagógica do professor. As autoras consideram que a implementação de materiais apostilados que uniformizam os conteúdos curriculares ministrados nas redes públicas de ensino suprimem as peculiaridades das escolas e servem como instrumentos de monitoramento explícito do trabalho pedagógico docente. Ball (2001b) revela que, no contexto da prática, mesmo em situação de controle, os professores conseguem recontextualizar o currículo padronizado vindo da SME/Rio às suas práticas de sala de aula. Neste contexto, Ball e Bowe (apud. MAINARDES, 2006) afirmam que o professor interpreta, reinterpreta e recontextualiza as políticas no contexto da prática. Marcondes (2013) afirma que os professores mesclam o currículo padronizado com suas crenças e experiências de prática pedagógica num processo de invenção. Para a autora, os docentes não recebem as políticas com pronta aplicação, eles as interpretam e as adaptam às condições locais, de acordo com suas experiências profissionais.

Carnoy (2002) revela que o aprimoramento, seleção e formação de professores como parte das políticas globais voltadas para a América Latina, vêm com o discurso de que a universidade não formava adequadamente os professores, sendo necessária uma formação específica para que estes pudessem ser mais eficazes no cumprimento das metas estabelecidas pelo Banco Mundial (BM) para a educação. Ball afirma que no processo de implantação de novas políticas educacionais "são estabelecidas novas identidades, novas formas de 
interação, novos valores" (2002, p. 6). E estes conceitos são passados aos professores através da formação continuada docente promovida pelo Estado.

No Brasil, estas ações foram implantadas pelos programas veiculados pela TV Escola (BRASIL, 2012a) para a formação dos professores à distância, visando auxiliar aos docentes na elaboração e aplicação de suas aulas nos moldes destas políticas. O texto a seguir exemplifica este aspecto:

A TV Escola é o canal da educação. É a televisão pública do Ministério da Educação destinada aos professores e educadores brasileiros, aos alunos e a todos interessados em aprender. A TV Escola não é um canal de divulgação de políticas públicas da educação. Ela é uma política pública em si, com o objetivo de subsidiar a escola e não substituí-la. E em hipótese alguma, substitui também o professor. A TV Escola não vai "dar aula", ela é uma ferramenta pedagógica disponível ao professor: seja para complementar sua própria formação, seja para ser utilizada em suas práticas de ensino. Para todos que não são professores, a TV Escola é um canal para quem se interessa e se preocupa com a educação ou simplesmente quer aprender (BRASIL, 2012a).

A Cidade do Rio de Janeiro também implanta ações de formação docente à distância através da Empresa Municipal de Multimeios (MULTIRIO) (RIO DE JANEIRO, 2012) que, nos moldes da TV Escola (BRASIL, 2012a), apresenta uma programação voltada para a formação docente e divulgação das ações políticas da SME/Rio, segundo a própria instituição se define:

A MULTIRIO - Empresa Municipal de Multimeios é uma empresa da Prefeitura do Rio de Janeiro, vinculada à Secretaria Municipal de Educação- SME. A MULTIRIO desenvolve ações educativo-culturais dirigidas à cidade, à escola, ao educador, ao aluno e à família. Por meio de seus produtos e canais de comunicação, promove a democratização da informação e do conhecimento, a atualização dos profissionais da educação, a aproximação e a integração social e o acesso da população aos bens culturais da cidade, estabelecendo um diálogo contínuo e permanente com educadores, alunos e sociedade, na construção coletiva do conhecimento e da cidadania (RIO DE JANEIRO, 2012).

Ball argumenta que a formação continuada "re-trabalha" os professores de forma que eles se tornem os promotores das "políticas de custo-benefício", de forma a cumprir as "metas de produtividade" (2002, p.7). E neste processo des 
reformas políticas, os textos curriculares passam a ter uma função estratégica de não só conduzir a formação dos alunos mas a conduta do professor no espaço da escola.

\section{OS DOCUMENTOS CURRICULARES NO CONTEXTO MICRO: A CIDADE DO RIO DE JANEIRO}

O currículo publicado pela SME/Rio vem atrelado aos modelos propostos pelas avaliações nacionais de larga escala, promovido pelas novas políticas. Para os gerenciadores das políticas no campo da educação, a própria noção de currículo passa por um processo de estreitamento, sendo reduzido a conteúdos programáticos mensuráveis, associando a educação à produtividade. Disciplinas como Leitura, Matemática e Ciências são consideradas como "mais importantes", de acordo com os grandes sistemas de avaliação, a exemplo do PISA 7 .

PISA is an international study that was launched by the $\mathrm{OECD}^{8}$ in 1997. It aims to evaluate education systems worldwide every three years by assessing 15-year-olds' competencies in the key subjects: reading, mathematics and science. To date over 70 countries and economies have participated in PISA (PISA, 2012).

currículo, como prática discursiva, serve ao propósito de facilitar o controle das instituições escolares através das avaliações em larga escala. Neste sistema, as políticas educacionais performáticas, empregam indicativos de avaliações, comparações e demonstrações como meio de controle e regulação (BALL, 2002). As performances individuais são interpretadas como demonstrações de "qualidade", merecendo premiações e promoções, em contrapartida à política de premiação, há as "punições" para as escolas que não conseguem atingir as metas estabelecidas, recebendo cada vez menos investimentos. Esse sistema de avaliação pela performatividade, enclausura 0 desempenho escolar a índices e metas pré-estabelecidos.

\footnotetext{
7 PISA - Programe for International Student Assessment (Programa Internacional de Avaliação de Estudantes).

${ }^{8}$ Organização para Cooperação e Desenvolvimento Econômico (OCDE) em Português, que consiste em fornecer uma plataforma de estudos para a solução de problemas de ordem econômica, onde os países membros são aqueles que detêm o maior Produto Interno Bruto (PIB).
} 
Ball (2002) afirma que o currículo passa a ter um discurso que serve ao mercado, priorizando conceitos e valores tais como a competição e o individualismo. As políticas performáticas responsabilizam alunos, professores, gestores e escolas pelo seu sucesso ou fracasso, isentando o Estado de qualquer tipo de responsabilidade. Como discurso, o texto curricular se torna 0 próprio texto da política, resultante de um campo de disputas e negociações.

Durante o processo de formulação dos textos curriculares, algumas vozes são contempladas e outras silenciadas. O currículo retrata ideologias, interesses, conceitos, embates legitimando ou não posturas e preceitos que devem ou não estar presentes nas escolas.

Por fim, quando o texto curricular chega às instituições escolares, já passaram por diversos processos de formulação e reformulação, podendo tornar-se "regimes de verdade". Ball e Bowe (apud. MAINARDES, 2006) propõem que os textos das políticas sejam analisados como os "discursos das políticas" servindo como instrumentos de poder e controle. Estudos curriculares que tratam a teoria do discurso como "texto político", nos permitem localizar os diversos tipos de discursos através do tempo, identificando as ideologias políticas contidas nos textos e apontando para os efeitos geradores de tais discursos (MAINARDES, FERREIRA e TELLO, 2011).

As políticas educacionais adotadas na cidade do Rio de Janeiro a partir de 2009, já vinham com o objetivo de uniformizar o currículo escolar através de parâmetros estabelecidos pelas avaliações padronizadas implantadas nas escolas públicas municipais da cidade, desenhando uma nova escala de valores no ensino escolar, onde a competitividade passa a ser uma prática respaldada pela SME/Rio. Os discursos de controle e de performatividade estão presentes nos documentos publicados pela SME/Rio, sendo dirigidos a escolas e professores e trazem diretrizes curriculares mais objetivas e prescritivas, conforme assinalado por Leite: "a SME tem seus documentos 
voltados para a lógica de transmissão de conteúdos, organizados de forma a se tornarem mensuráveis, por instrumentos de avaliação em formato de múltipla escolha" (2012, p.101).

O conjunto de políticas vigentes no atual governo de Eduardo Paes ${ }^{9}$ trazem como documentos curriculares oficiais: as Orientações Curriculares, os Descritores e os Cadernos de Apoio Pedagógico, juntamente com um sistema únificado de avaliação, as Provas Bimestrais.

As mudanças nas políticas da SME/Rio começou com a extinção dos "Ciclos de Formação"10, vigente nas políticas do governo anterior, e o retorno da seriação, a partir do $4^{\circ}$ ao $9^{\circ}$ anos do ensino fundamental, mantendo os indicativos de não reprovação nos três primeiros anos do ensino fundamental (1ํㅡㄴ $2^{\circ}$ e $3^{\circ}$ anos), com previsão de reprovação ao final do $3^{\circ}$ ano, a fim de priorizar o processo contínuo da alfabetização. As políticas educacionais no atual governo atrelam o desempenho à condição de "qualidade" na educação pública municipal.

Neste caso, o desempenho dos alunos reflete o desempenho das escolas e, consequentemente, sua classificação fica subordinada às regras estabelecidas pela SME/Rio. Ball (2002) critica essas políticas afirmando que os professores são classificados e premiados de acordo com o seu desempenho. $O$ trabalho docente é valorado de acordo com o desempenho demonstrado pela escola nas avaliações de larga escala patrocinadas pela SME/Rio. $O$ ato de ensinar e a criatividade docente são alterados para favorecer a competitividade e 0 individualismo como estímulo para que a gestão escolar desempenhe a função de monitoramento e controle sobre as práticas pedagógicas dos professores.

As novas políticas apresentadas pela SME/Rio publicam novos indicativos curriculares que priorizam as avaliações padronizadas nos moldes indicados

9 Eduardo Paes assumiu a Prefeitura da Cidade do Rio de Janeiro em 2009, venceu as eleições municipais em 2012 dando continuidade a seu governo, com previsão para findar em 2016.

10 Ver a esse respeito em Tura e Marcondes, 2011. 
pelo MEC, as denominadas Orientações Curriculares (RIO DE JANEIRO, 2009), que vêm organizadas como um planejamento anual, tendo uma grade ordenada em: Objetivos, Conteúdos, Habilidades, Bimestres e Sugestões, indicando ao docente um direcionamento visível dos conteúdos a serem ensinados aos alunos e, dentro de um tempo específico para que, ao fim de cada período, estes conteúdos sejam avaliados nas Provas Bimestrais. A SME/Rio exerce um controle mais sistemático sobre o processo de ensino e aprendizagem que acontece nas salas de aula das escolas. As Orientações Curriculares (RIO DE JANEIRO, 2009) apresentam uma diretriz prescritiva e instrucional, cerceando as ações pedagógicas dos professores.

Com as reformas, a prática profissional docente, ao moldar-se às políticas promovidas pela SME/Rio, serve aos propósitos de cumprir as metas de desempenho estabelecidas. Os critérios de "qualidade" estabelecidos por estas políticas são estanques e completos. É possível observar a organização dos conteúdos estabelecidos dentro de tempo estabelecido em bimestres para que os mesmos possam ser mensurados nas provas. Os documentos oficiais da SME/Rio não dão margem a questionamentos, mas, se apresentam com uma roupagem de acabamento.

Os Cadernos de Apoio Pedagógico são materiais entregues aos alunos contendo atividades relacionadas aos conteúdos cobrados nas Provas Bimestrais e que servem para auxiliar o docente no ensino dos conteúdos cobrados nas provas. A SME/Rio não só delineia estes conteúdos como interfere de forma direta nas estratégias de trabalho pedagógico ministradas sala de aula através das atividades dos Cadernos de Apoio Pedagógico que indicam ao professor como trabalhar os conteúdos cobrados nas provas.

O controle da SME/Rio sobre o trabalho docente não só se faz no produto final que são os resultados dos alunos nas provas, como também no processo de trabalho pedagógico do professor em classe, através do envio dos Cadernos de Apoio Pedagógico que contêm indicativos instrucionais de atividades a 
serem desenvolvidas em sala de aula. A avaliação valorizada nestas políticas não é aquela que prioriza as aprendizagens do aluno em situações cotidianas, mas, somente a avaliação do desempenho do aluno em situações de prova.

A SME/Rio inferioriza as demais formas de avaliação para considerar um único instrumento de avaliação aquilo que seja mensurável e quantificável: as provas objetivas de Língua Portuguesa, Matemática e Ciências, as Provas Bimestrais. Estas políticas podem resultar num impacto na autoestima dos professores, pois, estes percebem que há uma desvalorização visível das disciplinas que não são consideradas nas avaliações da SME/Rio.

As Provas Bimestrais são aplicadas aos alunos, sem que o professor tenha qualquer controle no processo de elaboração, aplicação e correção, aprisionando o fazer docente aos conteúdos cobrados nas provas (MARCONDES, 2013). Com isso, a autonomia do trabalho pedagógico em sala de aula fica reduzida ao ensino dos conteúdos que serão cobrados nas provas. E o desempenho resultante passa a ser o único referencial que indicativo da "qualidade" do trabalho pedagógico desenvolvido nas escolas.

Estas políticas de avaliação sistêmica deslocam os valores de autonomia, cooperação e criatividade para os valores de aferição, classificação e competição, trazendo como consequência o surgimento de disputas entre escolas e professores para que obtenham melhores resultados nas avaliações implantadas pela SME/Rio.

Outro instrumento curricular que serve como referência ao professor para ciência dos conteúdos que são cobrados nas provas da SME/Rio são os Descritores que se resumem a uma lista de habilidades relacionadas aos conteúdos de Língua Portuguesa, Matemática e Ciências. Os professores, ao início de cada bimestre, recebem esta lista de habilidades que devem ser trabalhadas com os alunos, pois, estas habilidades serão avaliadas pelas Provas Bimestrais. 
Os Cadernos de Apoio Pedagógico apresentam as atividades diárias e práticas relacionadas às habilidades presentes dos Descritores. Estes cadernos são distribuídos no início de cada bimestre para professores e alunos a fim de direcionar o trabalho pedagógico docente em sala de aula. Esse sistema apostilado tornou-se uma forma da SME/Rio uniformizar e conduzir as atividades pedagógicas que são trabalhadas na sala de aula (MARCONDES e MORAES, 2013).

O professor é submetido às lógicas do trabalho pedagógico voltadas para 0 "modelo de desempenho" e para a "transmissão dos conteúdos" (LEITE, 2012), pressionando os docentes a avançarem com o ensino dos conteúdos, independentemente do processo de aprendizagem dos alunos. Esta nova forma de relação do professor com os conteúdos e com a avaliação traz instabilidade e incerteza aos docentes. Eles têm consciência de que a avaliação do desempenho dos alunos volta-se contra eles e contra a escola. Marcondes (2013) afirma que os sistemas apostilados são elaborados para orientar os professores a preparar seus alunos para os testes. Ball (2002) faz críticas a modelos que priorizam a lógica de desempenho escolar e afirma que os professores são submetidos constantemente a pressões para aumentar o desempenho dos seus alunos nas avaliações externas.

Nossa pesquisa objetivou conhecer a opinião dos coordenadores pedagógicos, que trabalham em escolas do ensino fundamental da rede pública municipal da Cidade do Rio de Janeiro, a respeito dos materiais curriculares publicados pela SME/Rio.

Durante o processo de coleta de dados, entrevistamos dezoito coordenadoras pedagógicas que responderam questões referentes aos documentos curriculares e de avaliação enviados às escolas pela SME/Rio.

Todas as escolas de nossa amostra atendem aos primeiros anos do ensino fundamental e estão localizadas nos bairros da Jacarepaguá, Curicica, 
Taquara, Freguesia, Lagoa e Rio Comprido. As escolas selecionadas para esta amostra foram consideradas de "boa qualidade" pela SME/Rio porque alcançaram as metas de desempenho escolar na Prova Brasil de 2011, cuja média do IDEB para o Rio de Janeiro era de 5,4 (BRASIL, 2011). A comunidade escolar atendida é classe média baixa, formada de operários, autônomos e profissionais liberais.

As coordenadoras entrevistadas possuem faixa etária entre 33 e 62 anos e bastante experiência de trabalho docente que varia entre entre 15 e 41 anos. Todas assumiram a função de coordenação pedagógica a convite da diretora da escola. A formação acadêmica das coordenadoras é o terceiro grau completo, todas com formação no campo da Educação. Os nomes das coordenadoras citadas neste artigo foram modificados a fim de preservar suas identidades.

\section{OPINIÃO dOS COORDENADORES PEDAGÓGICOS A RESPEITO DO MATERIAL CURRICULAR ENVIADO PELA SME/RIO}

As coordenadoras pedagógicas trabalham nas escolas públicas do Rio de Janeiro com o objetivo de auxliar aos professores na compreensão e na aplicação do currículo vindo da SME/Rio. Elas se reúnem com os professores uma vez por semana para ajudá-los no processo de elaborar o planejamento das atividades pedagógicas de sala de aula, correção das Provas Bimestrais, e debates a respeito de assuntos internos da escola.

As coordenadoras pedagógicas se autodenominam "articuladoras" e "agentes de mediação" onde elas são a "peça chave na mediação entre a Secretaria de Educação e os professores da escola" (MARCONDES, LEITE, OLIVEIRA 2012, p.194). Essa mediação a qual as autoras fazem referência é a mediação política, onde, os textos curriculares são os próprios documentos das políticas. As coordenadoras entrevistadas têm consciência do papel de medição política que exercem na escola, pois, elas afirmam que "tem que mediar as políticas 
que vêm da Secretaria, as propostas que vêm da Secretaria com a proposta de trabalho da escola" (coordenadora Fábia, entrevista realizada em 2013). A "proposta de trabalho" a qual a coordenadora Fábia faz referência é o projeto pedagógico da escola. O projeto pedagógico, ao contrário dos textos curriculares da SME/Rio, se caracterizam por se identificarem com as peculiaridades da escola, por atenderem às características específicas de cada escola.

Neste contexto, as coordenadoras consideram que o material curricular enviado pela SME/Rio como "importante" porque os conteúdos presentes no material serão cobrados nas Provas Bimestrais.

A coordenadora Ângela (entrevista realizada em 2014) relata que "os cadernos pedagógicos são nosso fio condutor porque as provas são em cima deles." Isso revela que as coordenadoras consideram o material curricular da SME/Rio "importantes" demonstrando que, numa avaliação classificatória, os índices obtidos nas provas dará a escola o rótulo de "escola boa" ou "escola ruim". Ball considera que as avaliações "servem como medidas de produtividade ou resultado, demonstrações de "qualidade", ou "momentos" ou inspeção" (2012, p. 37).

O monitoramento das escolas através das Provas Bimestrais revela o caráter performático da educação municipal do Rio de Janeiro. As Provas Bimestrais são elaboradas com base no material curricular da SME/Rio: Orientações Curriculares, Descritores e Cadernos de Apoio Pedagógico. Marcondes e Moraes (2013) entendem que as Provas Bimestrais voltam-se apenas para 0 sistema classificatório onde o objetivo é obter bons resultados nos testes.

As coordenadoras revelam que os materiais enviados pela SME/Rio passaram a ser fundamentais no trabalho dos professores em sala de aula porque as Provas Bimestrais acabaram moldando o trabalho pedagógico docente nas escolas. A coordenadora Tatiana (entrevista realizada em 2014) relata que: "a 
pressão é tão grande dessas apostilas para dar conta...". A coordenadora Janaína (entrevista realizada em 2014) afirma que os Cadernos de Apoio Pedagógico "são usados todos os dias pelos professores". E a coordenadora Priscila (entrevista realizada em 2014) diz que "a gente prioriza as Orientações Curriculares, ao mesmo tempo que tenta focar nos Descritores mesmo". O "foco" nos Descritores enfatiza que as habilidades trabalhadas em sala de aula são consideradas como prioritárias para as coordenadoras por causa das avaliações.

Podemos observar que o material curricular enviado pela SME/Rio passou a ser o currículo principal utilizado nas escolas pelos professores por causa das avaliações em larga escala. $O$ indicador de uniformização curricular é evidente nas falas das coordenadoras pois revelam que as Provas Bimestrais acabaram determinando o direcionamento do trabalho pedagógico dos professores das escolas pesquisadas.

Isso mostra um forte estímulo da SME/Rio sobre as escolas para o uso do material uma vez que este está diretamente atrelado às avaliações de larga escala promovidas pela SME/Rio.

Marcondes e Moraes (2013) defendem que as avaliações de larga escala como as Provas Bimestrais facilitam o monitoramento do Estado e permite que elas interfiram nas práticas pedagógicas das escolas transformando o trabalho pedagógico em resultados mensuráveis, e ainda, associa estes resultados a indicadores de "qualidade". No entanto, as autoras consideram que estas práticas diminuem a autonomia do professor. Nestas políticas, aqueles que trabalham nas escolas são considerados como meros reprodutores dos textos curriculares oficiais em sala de aula e que necessitam unicamente destes materiais para realizar seu trabalho pedagógico. As coordenadoras entrevistadas revelam que, apesar das políticas de controle, buscam seus próprios caminhos com base em seus valores, experiências e vivências da prática de sala de aula para auxiliar os alunos no processo de aprendizagem, 
principalmente nos primeiros anos do ensino fundamental onde a prioridade é a alfabetização.

As coordenadoras relatam que efetuam atividades de "reforço escolar" (coordenadora Sarah, entrevista feita em 2013) para os alunos que apresentam "dificuldades de aprendizagem". Ela informou que ela mesma trabalha com os alunos que apresentam "dificuldades" em leitura e escrita. A coordenadora Fábia (entrevista feita em 2013) orienta os professores a trabalharem em sala com a "recuperação paralela" na qual alguns alunos que apresentam baixo desempenho, fazem atividades diferenciadas dos demais alunos da turma.

As coordenadoras participantes desta pesquisa perceberam que é necessária a busca da escola de um caminho para sanar os "problemas de aprendizagem" dos alunos. Assim, na visão delas, eles passam a apresentar bons resultados nas Provas Bimestrais. Marcondes (2013) mostra que há uma "submissão" por parte de coordenadores e professores frente às políticas avaliativas, porém, há também a "invenção" quando eles criam estratégias próprias para superar os desafios existentes nas escolas. Porém, percebemos que as estratégias de superação das "dificuldades de aprendizagem" dos alunos, são voltadas para a melhoria do desempenho discente nas Provas Bimestrais.

\section{CONSIDERAÇÕES FINAIS}

Nossas considerações revelam que as políticas globais influenciam na políticas locais, sendo possível verificar que o contexto local se torna um reflexo das políticas do campo macro. No contexto brasileiro, observamos que os governos da esfera federal implantaram políticas que favoreceram o fortalecimento da responsabilização e performatividade existentes na Cidade do Rio de Janeiro no campo educacional. O sistema de premiação e de avaliação em larga escala trouxe como consequência mudanças na postura pedagógica de coordenadores pedagógicos e professores em relação ao currículo e à avaliação discente. 
Carnoy (2002) mostra como as políticas do campo macro que influenciam as relações econômicas, de trabalho e no campo das políticas educacionais trazendo os ideais empresariais para o interior das escolas. Ball e Bowe (apud. MAINARDES, 2006) revelam como os discursos das políticas estão sempre no campo das disputas, tanto no em sua elaboração quanto no contexto da prática, no caso as escolas. Ball (2001b) afirma que gestores e professores, ao tomarem ciência da prescrições das políticas, as interpretam, reinterpretam e as recontexutalizam de acordo com suas crenças, experiências e contextos onde as escolas estão inseridas.

O campo situado que apresentamos neste trabalho são as escolas públicas municipais da Cidade do Rio de Janeiro. As políticas oficiais estão alinhadas nos moldes da responsabilização quando o currículo vigente passou por um processo de padronização e os instrumentos de avaliação são aqueles enviados pela SME/Rio às escolas, as Provas Bimestrais. A diretriz pedagógica docente tem como base as Orientações Curriculares, os Descritores e os Cadernos de Apoio Pedagógico que são enviados às escolas a cada bimestre com os conteúdos e habilidades que serão cobrados nas avaliações periódicas da SME/Rio.

Nas entrevistas com as coordenadoras pedagógicas atuantes em escolas das primeiras séries do ensino fundamental, percebemos que elas consideram os materiais enviados pela SME/Rio às escolas como "importantes" porque elas sabem que os conteúdos e habilidades contidos nos materiais serão cobrados nas Provas Bimestrais. Elas revelam que "há uma pressão" por parte da $\mathrm{SME} /$ Rio para o uso dos materiais curriculares por isso eles são "utilizados diariamente pelos professores" em sala de aula.

As coordenadoras relatam que, ao mesmo tempo em que os professores utilizam frequentemente o material da SME/Rio em sala de aula, eles criam estratégias criativas para sanar os "problemas de aprendizagem" apresentados 
pelos alunos de suas escolas, tendo como objetivo a melhoria do desempenho dos alunos nas Provas Bimestrais.

Consideramos que a lógica da avaliação padronizada desconsidera outras formas de conhecimento e de aprendizagem tornando relevante apenas os conhecimentos mensuráveis que são medidos em provas objetivas. Nas atuais políticas, as coordenadoras relatam que as avaliações de larga escala restringem as ações pedagógicas e reduzem a criatividade docente. Ao mesmo tempo que as políticas no nacionais, como a LDB (BRASIL, 1996a) tratam da autonomia escolar indicando que a escola pode elaborar sua proposta pedagógica (Ibid.), o sistema de avaliação em larga escala indica os conteúdos e áreas do conhecimento escolar que são consideradas na Prova Brasil (BRASIL, 2011). Por isso, Marcondes e Moraes (2013) afirmam que estas duas lógicas são irreconciliáveis.

Consideramos que as políticas de avaliação deveriam servir para direcionar investimentos governamentais e trazer benefícios a todos que trabalham e utlizam a escola pública não para apenas classificar escolas, gestores, professores e alunos. As políticas performáticas reduzem os docentes a técnicos aplicadores de sistemas apostilados e de avaliações padronizadas.

Defendemos a autonomia, o compartilhamento de experências pedagógicas bem sucedidas entre os docentes dentro e entre escolas e um sistema de avaliação que possa valorizar o trabalho pedagógico dos professores assim como as aprendizagens dos alunos em situações cotidianas. Pensamos as avaliações em larga escala não para servir como fator de premiação ou punição, mas, pensando em políticas locais que visem atender aos desafios existentes nas escolas, além de uma verdadeira valorização docente.

O currículo deve ter uma parte comum e uma parte de constructo identitário com as peculiariadades de cada escola. O diálogo entre governos e aqueles que participam diretamente do processo educacional municipal deve ser constante para que $o$ documento currícular oficial realmente seja a 
representação local de escolas e comunidades. Por fim, a formação continuada docente sirva para a superação de desafios de ensino e aprendizagem, de acordo com as diversas realidades encontradas. Por isso, encontros peródicos entre os professores a fim de compartilharem suas experiências docentes deveria ser estimulada, ao invés de dificultada.

\section{REFERÊNCIAS}

BALL, S.J. Diretrizes políticas globais e relações políticas locais em educação. Currículo sem fronteiras. v.1, n.2, 99-116p., jul-dez 2001a.

BALL, S.J. Cidadania global, consumo e política educacional. In: SILVA, L.H. (Org.) A escola cidadã no contexto da globalização. 5 ed. Petrópolis, Vozes, 121-137p., 2001b.

BALL, S.J. Reformar escolas/reformar professores e os terrores da performatividade. Revista portuguesa de educação. ano/vol.15, n.2, Braga, Universidade do Minho, 3-23p. 2002.

BALL, S.J. Performatividade, privatização e pós-estado do bem-estar. Revista Educação e Sociedade. Campinas, Universidade de Campinas, v.25, n.89, 1105-1126p., set-dez 2004.

BALL, S.J. Reforma educacional como barbárie social: economismo e o fim da autiencidade. Revista Práxis Educativa. Ponta Grossa, Universidade Estadual de Ponta Grossa, v.7, n.1, 33-52p., jan-jun 2012.

BRASIL. Lei № 5537 de 21 de novembro de 1968. Cria o Instituto Nacional de Desenvolvimento da Educação Básica e Pesquisa (INDEP) e dá outras providências.

Disponível em: <www.planalto.gov.br/ccivil 03/Leis/L5537.htm> Acesso em 6 fev 2015.

BRASIL. Lei № 9394 de 20 de dezembro de 1996a. Estabelece as diretrizes e bases da educação nacional. Disponível em: $<$ http://www.planalto.gov.br/ccivil 03/leis/L9394.htm $>$ Acesso em 25 ago 2012.

BRASIL. Emenda Constitucional № 14 de 12 de setembro de 1996b. Modifica os artigos 34, 208 e 212 da Constituição Federal e dá nova redação ao artigo 60 do Ato das Disposições Transitórias. Disponível em: $<$ www.planalto.gov.br/ccivil 03/constituicao/Emendas/emc14.html $>$ Acesso em 6 fev 2015.

BRASIL. Parâmetros Curriculares Nacionais: introdução. Brasília, Ministério da Educação e do Desporto, 1998.

BRASIL. Lei Federal № 11494 de 20 de junho de 2007. Disponível em: 
<www.planalto.gov.br/ccivil 03/ato2007-2010/2007/lei/l11494.html>

Acesso em: 6 fev 2015.

BRASIL. PDE/Prova Brasil: Plano de desenvolvimento da educação. Brasília, MEC; SEB; INEP, 2011.

BRASIL. Ministério da Educação. TV Escola. Texto de apresentação. Disponível em: <http://tvescola.mec.gov.br/index.php>. Acesso em: 22 dez 2012a.

BRASIL. Índice de Desenvolvimento da Educação Básica. Ministério da Educação. Disponível em: <http://portal.mec.gov.br/index.php> Acesso m: 25 ago $2012 b$.

BRASIL. Apresentação Programa Dinheiro Direto na Escola - PDDE. Disponível em: <www.fnde.gov.br/programas/dinheiro-diretoescola/dinheiro-direto-escola-apresentacao> Acesso em 6 fev 2015.

CARNOY, M. Mundialização e reforma na educação: o que os planejadores devem saber. Brasília, UNESCO, 2002.

FREITAS, L.C. Políticas de responsabilização: entre a falta de evidência e a ética. Cadernos de Pesquisa. São Paulo, Fundação Carlos Chagas, v. 43, n. 148, 348-365p., jan-abr 2013.

LEITE, V.F. A atuação da coordenação pedagógica em conjunto com os professores no processo de recontextualização da política oficial no $1^{\circ}$ ano do ensino fundamental no município do Rio de Janeiro. Tese de doutorado. Rio de Janeiro, Pontifícia Universidade Católica do Rio de Janeiro, 160p., 2012.

MAINARDES, J. A abordagem do ciclo de políticas: uma contribuição para a análise de políticas educacionais. Revista educação e sociedade. v.27, n.94, Campinas, Universidade de Campinas, 47-69p., jan-abr 2006.

MAINARDES J.; FERREIRA, M.S.; TELLO, C. Análise de políticas: fundamentos e principais debates teórico-metodológicos. In: BALL, S.J.; MAINARDES, J. (Orgs.) Políticas educacionais: questões e dilemas. São Paulo, Cortez, 143-174p., 2011.

MARCONDES, M.I., LEITE, V.F.A., OLIVEIRA, A.P. Reforma e recontextualização das políticas: o papel dos coordenadores pedagógicos nas escolas municipais do Rio de Janeiro. Revista Diálogo Educacional. Curitiba, Pontifícia Universidade Católica do Paraná, v.12, n.35, 187-209p. jan-abr 2012.

MARCONDES, M.I. Professores, currículo e didática: desafios frente às novas políticas de sistemas apostilados na rede pública. FAVACHO, A.M.P.; PACHECO, J.A.; SALES, S.R. Currículo, conhecimento e avaliação: divergências e tensões. Curitiba, Editora CRV, 137-153p., 2013.

MARCONDES, M.I.; MORAES, C.L. Currículo e autonomia docente: discutindo a ação do professor e as novas políticas de sistemas apostilados na rede pública de ensino. Currículo sem fronteiras. v.13, n.3, 451-463p., set-dez 
2013. Disponível em: <www.curriculosemfronteiras.org > Acesso em: 21 mar 2014.

PISA. About Pisa. Disponível em: <http://www.oecd.org/pisa/> Acesso em: 22 dez 2012.

RIO DE JANEIRO. Orientações curriculares de Língua Portuguesa. Rio de Janeiro, Secretaria Municipal de Educação, 2009. (circulação interna)

RIO DE JANEIRO. Decreto № 333399 de 16 de fevereiro de 2011. Dispõe sobre os critérios de premiação a ser concedida aos servidores na forma que menciona. Diário Oficial do Município do Rio de Janeiro, Rio de Janeiro, Imprensa municipal. 17 fev 2011. Disponível em: $<$ https://leismunicipais.com.br/a/ri/r/rio-de-janeiro/decreto/2011/3339/33399>. Acesso em: 08 abr 2016.

RIO DE JANEIRO. Multirio - Empresa Municipal de Multimeios Ltda. Disponível em: <http://www.rio.ri.gov.br/web/multirio/principal > Acesso em: $23 \mathrm{dez}$ 2012.

TURA, M.L.R.; MARCONDES, M.I. O mito do fracasso escolar e o fracasso da aprovação automática. Cadernos de Educação. Pelotas, Universidade Federal de Pelotas, n.38, 95-118p., jan-abr 2011. 